\title{
Caring Style Mediation a New Form of Medical Dispute Alternative Dispute Resolution in Taiwan
}

\author{
Shih-Ying Lee*, Yong-Chi Chen \\ Chen Chung Chwen Memorial Doctor-Patient Relationship Promotion Educational Public Welfare Trust Fund(CDPET), Taipei, Taiwan
}

\section{Email address:}

cyclee1688@gmail.com (Shih-Ying Lee), cyclee168@kimo.com (Yong-Chi Chen)

\section{To cite this article:}

Shih-Ying Lee, Yong-Chi Chen. Caring Style Mediation a New form of Medical Dispute Alternative Dispute Resolution in Taiwan. American Journal of Clinical and Experimental Medicine. Vol. 3, No. 6, 2015, pp. 350-354. doi: 10.11648/j.ajcem.20150306.15

\begin{abstract}
This article aims to discuss new style medical mediation-Caring Style Mediation (CSM) a form of alternative dispute resolution (ADR). First, a description of current medical dispute mediation in Taiwan, 2nd, the contents of CSM were introduced. Then, we discoursed the introduction of Japanese's style Internal Hospital Mediation into Taiwan and subsequently developed into CSM. Finally, we discuss the future promise of CSM in medical dispute and Safety and Quality of medical care.
\end{abstract}

Keywords: Medical Dispute, Caring Style Mediation, Medical Mediation, Alternative Dispute Resolution

\section{關懷式調解-新型態醫療糾紛的訴訟外解決機制}

\section{李詩應*, 陳永綺}

陳忠純紀念促進醫病關係教育公益信託推廣會, 臺北市, 臺灣

\section{邮箱}

cyclee1688@gmail.com(李詩應), cyclee168@kimo. com(陳永綺）

摘要：本文討論新型態的醫療糾紛訴訟外解決機制關懷式調解在台灣的展開論述。關懷式調解與醫療糾紛訴訟外處理 機制的調解差異。接著介紹從日本引進其特有的醫療促進溝通調解模式到台灣, 種種經過與發展情況至第四波調解一 關懷式調解。最後論述醫療糾紛關懷式調解在台灣的展望。

关键词: 醫療糾紛, 關懷式調解, 醫療糾紛調解, 訴訟外處理機制

\section{1. 引言}

ADR到底包含那幾種, 有不同看法: 最廣義包含談判 交涉（Negotiation）、調解（Mediation）、調停 (Conciliation)、仲裁（Arbitration）、混合型、以 及預防糾紛的技巧; 最狹義的只有指調解。 [1] 通說大 致與臺灣醫療糾紛ADR相同認為, 主要指調解 (一般、法 院）、調處（行政）、及仲裁三者。台灣民法上和解 (Settlement) 與民訴程序上指的和解 (Negotiation to Settlement）是不同概念, 然而大部份法律文書均使用相 同字句「和解」。[2] 調解的定義指的是第三方協助達
成和解, 所以調解指的是程序, 而達成的效力是和解 (Settlement)。本文建議最好分別出效力上的和解 (settlement) 與程序上的和解 (negotiation), 改為 交涉談判較妥, 以免混淆。

調解方式上可分為華人傳統調解 [3]，以及現代調 解。華人傳統調解以身份地位並以指責方式找出雙方缺失 為主來達成調解成立, 常有誤解認為這是一種評價式調解 (Evaluation Mediation)，然而本文見解認為華人傳統 調解應屬評判式調解 (Judgmental Mediation)。現代調 解指的是從美國龐德 (R. Pound) ADR理念的開啓至1976 龐德會議召開後正式開始。[4] 現代調解主要指評價式、 
促進式、轉換型 [5]、其他尚有問題解決型 [6]、敘事 型 [7] 及混合型等。台灣學者目前對醫療糾紛調解的認 知多只分為評價與促進兩種, 並以評價式調解為主。[8] 雖然有學者試圖探討現行相關法令下的調解類型屬性, 惟 依其原則恐除民事訴訟法明文採用「評價式調解」外，其 餘均偏促進式調解為主。［9]不過筆者在此議題所為接 觸實際從事醫療糾紛調處與調解專家的經驗, 鮮少有正確 認知促進式調解的概念。大多是以專家之評價意見為主, 較少考慮雙方之自主性解決, 就是以專家看完資料後認定 誰對誰錯, 提出應該如何解決的看法來勸（或責罵）雙方 接受。這是與現代調解真意背道而馳的做法, 與古時候宗 親長老、地方士紳主持公道做法雷同, 在現代民眾自主權 力高張、知識爆炸、各方專家權威信賴度瓦解、以及醫療 分科精細等等因素之下, 因此可以了解其效果不彰現象的 根本原因。

本文即希望提出現代調解之各種類型, 結合引進日本 混合式調解三年經驗及省思, 藉以提出關懷式調解是作為 最適合醫療糾紛ADR之一種調解型態。

\section{2. 材料和方法}

從現代調解三波段進展及其中主要的四種調解論述 找出符合華人社會醫療爭議或糾紛的調解型態。首先論述 從美國南加州開始現代調解三波段之演進, 接著是四種主 要調解特色, 分述如下:

\section{1. 現代調解三波段進展}

調解第一波: 美國1976年龐德會議正式展開ADR為現 代調解之開始為多數人所認同, 其基礎包含了衝突管理、 心理學進展及社區需求, 尤其是商業的時間就是金錢等外 界條件成熟。調解第二波: 更細緻化的調解方法開始出現, 包括促進式與轉換式等等。調解第三波: 案主中心的體現, 以日本和田教授為主的醫院內溝通調解, 混合了轉換型、 促進型、評價型及敘事型調解四種, 並以敘事型為其特色。 [10］以下簡要論述這四種調解。

\section{2. 四種調解概述}

\subsection{1. 轉換型}

在複雜的醫療糾紛模式裡, 最先要使用轉換型模式。 雖然只有靠它是不夠的, 但卻是最重要的。以關懷的理 念為基礎, 堅信處於問題的當事人，原本就具備自我療 癒的能力。這也是心理學的精微心理諮商 (Micro counseling）學派相信人具備正面的力量, 只要給予適 度支持與協助, 可以自己走出傷痛。轉換式調解最重要 的就是改變當事人的認知框架, 只要鬆動一點點, 就能 有改變契機。調解員的課題是要協助因衝突陷入一片混 亂的人, 完成自我療癒。雖然和心理諮商有些相同, 但 仍有根本性的不同。[11]

轉換型調解有兩個重要詞語, 一個是Empowerment充 權, 是提升的意思, 就是自我成長。再來是Recognition 認可或承認。這也是心理學的轉變, 就是要了解這件事情
可能有其他的解讀方法, 而不是只有原本想的這個樣子, 如果有點意識到而改變, 就有機會繼續進展。 [11]

\subsection{2. 促進型}

促進型最主要特點就是把衝突區分為表面的主張、議 題和隱藏在主張下面的欲求。表面主張是Position, 議題 是Issue, 隱藏在主張下面的欲求是Interest, 簡稱為IPI。 [11] 這就是哈佛交涉術所提到的, 在和對方交涉的時候 要追求雙贏, 因此要去分析到對方隱藏在主張下面的欲求, 了解以後在不違背自己想要的原則下, 盡量滿足對方的需 求。 [12]

促進型的調解模式精髓就是IPI, 是一種覺察能力, 能了解當事人的深層想法, 就有可能找到解決的契機。

如果一開始就以促進式模式來進行調解並不合適，因 為在醫療糾紛的案件發生時, 常帶著很多的情緒, 因此情 緒是最先要處理的問題。接著才能以促進式的方式進行對 話。運用覺察力-IPI, 如此才可以做到很深層、很多層次 的讓醫病雙方有思考的空間和時間。很多情況病人要什麼 或是醫護人員要什麼, 一開始往往也不清楚, 必須透過調 解員的協助, 慢慢可以想通想要的是什麼, 甚至接受現實 的無奈。 [13]

\subsection{3. 評價型}

評價型調解的調解員會作出專業的判斷, 並採取主 導對話方向性的方式進行調解。雖然大部分研究或從事 $\mathrm{ADR}$ 的人認為評價式的調解不適合醫療糾紛, 但還是有其 必要性, 尤其是在某些時候是可以在 $100 \%$ 信任之下, 而 且想要積極的解決大家都已經知道問題的時候, 調解員 在這樣的基礎下, 鎖定問題核心, 而且用專業導入解決 方案, 就能發揮評價型優點加快速度, 讓彼此雙方達到 共同目標。 [13]

評價型調解畢竟還是現代調解的一種, 仍然希望能夠 協助當事人達成協議並解決糾紛, 但是它是比較積極介入, 而且是積極表達自己身為該領域專家的見解。這樣的方式, 在醫療糾紛比較不是那麼合適。本文見解, 目前台灣醫療 糾紛調解模式大部分還是因為時間的急迫性與既有的慣 性思考下, 或者是身處此文化的人常常不知不覺就受到影 響, 採取和傳統文化比較接近的評判式調解 (Judgmental mediation) 型態模式來解決。在醫療爭議調解案例中, 評價型只建議運用在最後必要性階段。

\subsection{4. 敘事型}

源自敘事心理學及敘事醫學的發展, 慢慢因而有了敘 事型調解的提出。敘事型調解是從敘事醫學概念在醫療領 域先提出來的, 然後, 把此理念運用在調解, 稱為敘事型 調解。用描述故事的方法架構「現實」, 再在內心重新描 述「現實」, 進而達成「現實」的改變。 [13]也就是利 用認知框架, 來了解衝突的對立, 並改變這樣的架構, 才 能夠對醫糾雙方當事人, 達成真正永久性高品質的解決, 只有從認知框架去解碼、運用衝突管理及敘事著手加上關 懷理念來解開心中的糾葛, 才有辦法, 也才是真正解決問 題的方法。 


\section{3. 結果與討論}

\section{1. 引進台灣三年經驗}

從2103年1月開始, 經過在台灣參與醫療糾紛相關的 多種活動三年, 這些活動包括: 一、課程上：13回兩天基 礎課程訓練學員共約190位、一般概念講師培訓17位、醫 學院及法學院學生講座、醫院理念推廣演講、座談會及小 型半天體驗式課程等。二、實務上: 參與台北市衛生局及 台北地院醫療糾紛調解委員、醫療爭議之醫院輔導訪查等。 三、政策上: 參與掌管醫院評鑑及醫事人員再教育的財團 法人醫院評鑑暨醫療品質策進會 (簡稱醫策會) 的醫療爭 議關懷小組推動、多方請教先進交換意見等。除了積極將 此理念、課程與實務融入臺灣醫療環境內, 我們公益信託 成員還持續與國際接軌: 一為繼續與日本交流, 2014/9/17-18參訪日本法院與醫院的實際運作情況。二為 2014/8/5-8赴山西參加包括英、美、日、中、台、香港等 學者專家參與之國際醫療糾紛調解理論與實務研討會。三 為參加發表論文于南京2014/10/24-26舉行之第五屆海峽 兩岸醫藥法律論壇。四為參加2015/09/27-29香港舉行亞 洲醫療安全與品質研討會發表壁報論文。五為 2015/10/5-11二度參訪日本, 討論進展及明年計劃。六為 2015/10/28-29台北第六屆海峽兩岸醫事法學術研討會發 表口頭報告。七為2015/12/9-10此次大陸杭州主辦之國際 醫療健康研討會發表論文。

\section{2. 台灣相關法草案立法經過}

自行政部門將醫療糾紛處理法與補償條例草案 (簡稱 醫糾處理法）送交立法院討論後, 已經完成二讀通過, 只 差一個針對各界出資比例條文無法取得共識, 離通過立法 院三讀正式成立, 幾乎可說是只欠臨門一腳, 指日可待。 但卻爆發出醫界前所未見的反彈聲浪, 最後不少原先支持 團體, 紛紛表示雖認同這個草案精神, 但存有疑慮, 因此 予以擱置, 確定無法在此屆立法委員任期（將於 2016/01/16重新改選）內通過立法。［14］下一任開始， 需重新送審歷經三讀才能通過, 回歸從零開始。不過關懷 理念及成員之運作，已經透過主管機關輔導及督導考核, 以及醫策會的評鑑條例等政策上去要求, 而持續展開, 但 依民間監督團體醫改會資料認為仍然是處於有名無實之 狀態, 亟待努力。 [15]

最新的進展是溝通關懷理念在「生產風險救濟條例草 案」順利列入並完成一讀。這是承襲自2012年開始的「生 育事故救濟試辦計畫」因為成效斐然, 降低產科醫療糾紛, 改善執業環境的基礎 [16]。一般認為這是主管機關本想 以直接通過醫糾處理法來擴大實施, 但因為醫糾處理法觸 礁, 所以轉由爭議較小的這個草案先行通過, 作為將來擴 大的基礎。本文見解贊同這種務實漸進的方式來推動。

\section{3. 台灣現有醫療糾紛調解類型之比較}

雖然台灣醫療糾紛調解模式大部分都是偏評判的評 價式, 但是, 學者冷函芸提出, 認為醫糾和其他某些類型 的爭議調解是促進式的調解。就台灣現有法律具體觀察而 言, 著作權爭議調解辦法第 12 條, 就當事人意見為適當的
勸導, 實際情況及爭議重點為調解。台灣的醫療爭議調處 作業要點第 9 點, 調解委員依案件性質、爭議內容、雙方 期望等情事, 引導當事人達成調處, 是促進式。評價式則 舉民事訴訟法第 414 條, 酌擬平允方案, 力謀雙方和諧為 例。 [9]

在醫療糾紛調解和調處, 有四個辦法來規範, 第一個 是衛福部的作業要點, 台北市則訂有自治條例第 16 條, 調 處委員依案件性質、當事人期望、迅速調處等必要性考量, 決定程序引導當事人達成調處。民事訴訟法第 414 條、鄉 鎮市調解條例第22條, 有酌擬公正合理辦法, 力謀雙方 之協和。醫糾調解四個規範上, 學者認為其中兩個是促進 式，兩個是評價式。［9]

不過本文見解認為其文章內容可能太過二分法, 沒有 其他調解概念的融入, 並不是那麼理想。實則未必一定是 評價式或促進式, 而且調解是重於技巧及溝通的解決途徑, 不應該單純只分別促進式調解與評價式調解, 應把兩個調 和, 兩相結合。當然如果能學得越多方法, 視情況來用, 是最好的辦法。前提是要很了解每一種調解的作用、意義, 整個環境適合什麼, 還要深入了解雙方當事人, 以及自己 的能力, 才能做出最好的決定。 [13] 譬如: 評價式調解 是主、客觀都與行為都有評價的傾向, 比較重視結果, 對 成功率比較在意, 不計一切代價只想要讓調解成立; 促進 式調解是過程取向, 重視在過程當中的每一細節, 雖然結 果不滿意, 還是對雙方有幫助。 [13] 如此多方比較, 運 用在調解時, 就能即時反應達到最好的效果。

\section{4. 第四波調解型態-關懷式調解}

接續三波段現代調解的引進, 在台灣三年經驗以及多 次海峽兩岸交流之下，我們提出第四波的調解一關懷式調 解 (Caring Style Mediation-CSM), 符合華人社會醫療 爭議糾紛的ADR模式。CSM可分為關懷與調解及程序三部分 探討。

\subsection{1. 關懷}

關懷可以細分為 $\mathrm{CS}_{\mathrm{P}+\mathrm{M}} \mathrm{I}$ 三個子項。CSI都具足才是真正 的關懷。

C-Concerning關心，是對某件事或某個（群）人的關 注。關心的範圍常常決定了層次高低與最後的結果好壞。 心態上的調整, 才能改變關心的範圍。這也是為什麼源自 日本的基礎工作坊需要兩天的最大原因。

S-Support支持:物質上physical與心理上mental兩方 面的支持，也可以說是物資上的資源及純心理上支援。但 是有時物質上的會隱含或可以間接專換成心理上的支援。

I-Improvement改進與成長，關懷據Milton Mayeroff 所寫關懷的力量一書定義上, 即包含期望對象 (人或事) 的改進與成長。 [17]

\subsection{2. 調解}

調解為混合式上述四種調節, 加上衝突管理作為基礎、 靈活的綜合運用。再佐以美國調解程序上當事人自主意願 極大化尊重來進行, 也就是讓當事人自由選擇調解方法、 場所、議題及調解員。 


\subsection{3. 程序}

程序是由醫療院所內或外人員進行至少做到對醫療 爭議雙方當事人的關懷，協助各方整合各自分歧意見，並 視情形在醫療院所內或外進行一部或全部調解。一部調解 時, 未決部分可以結合醫師公會、專科學會、或鑑定報告 意見, 或是尋求仲裁、甚至是訴訟程序等就金額部分, 尋 求雙方合意可以接受之決定辦法。即使無法達成和解協議, 也已經處理負面、混亂等情緒, 可以作為將來院外程序調 解、訴訟等作為穩固基礎, 持續給予協助支持, 以加強ADR 解決爭議之成功率。

\section{4. 結論}

現有台灣醫療爭議 (包含客訴及糾紛) 處理模式有 1 . 院內雙方交涉、2. 調解: 調處、鄉鎮市、法院、仲裁 3 . 訴訟等, 這些各階層之處理模式都跟所有專業一樣, 重在 針對「事」的處理，息事寧人形式上的解決。缺少的是對 「人」的關懷, 也就是希望能做到實質上的解決。

外在環境趨勢非常有利於關懷式調解在台灣的發展, 其原因為：1. 修法趨勢已將溝通關懷納入修法內容。2. 對應醫療環境的愈趨險惡, 醫護人員更需具備如此溝通關 懷的理念以自保保人, 因此需要的師資人才將會劇增。3. 法院與各衛生局及衛福部高層管理單位也意識到關懷與 調解為處理醫療爭議糾紛的趨勢與重要。

現今台灣醫療糾紛調解仍以院外第三方調解, 其樣式 多以偏向評判的評價式調解為主, 醫院內則以雙方交涉談 判為主, 且多以對立方式非以真正隻贏心態來進行, 少有 促進式調解概念, 更不用說尚無醫療促進溝通調解這種概 念, 亦即溝通關懷調解。雖然近幾年來, 醫療糾紛頻傳, 醫界業已做了多方的改善方式, 許多醫院高層多認為院內 已有相關人與促進溝通關懷的處理機制, 但深入接觸後就 會發覺其心態目標設定及處理之當事人感受會有極大不 同之處。醫療促進溝通調解是一門有著諸多學理基礎, 且 集溝通、交涉、關懷的綜合應用技巧, 就像武術中的柔術, 以柔克剛、化力消強, 以暴止暴、以強力對強力從來都不 是能真正解決問題的辦法。柔術看似沒什麼力量, 卻是真 正能解決問題之唯一正途。所以醫療促進溝通調解經過引 進推廣及省思後的關懷式調解應該是台灣醫療糾紛訴訟 外處理機制的最佳處理心態與機制之一。

我們從2013年在台灣開始介紹及推廣日本綜合轉換 式、促進式、評價式及敘事式調解一醫療院內促進溝通調 解, 又稱溝通關懷 [18]。將近三年左右, 更提出關懷式 調解 (CSM)。而由ADR進展至糾紛管理專業人員化 (Dispute Management Specialist-DSM) 將會是潮流趨勢。院內溝 通關懷調解正是符合此潮流趨勢。 [19]

日本式促進溝通調解引進並進一步形成關懷式調解, 對於台灣醫療爭議之預防及減輕衝擊已經漸有成效, 甚且 對促進醫病關係方面有著重大突破, 開始廣受各界讚許。 [20-24]訴訟無法解決所有醫療糾紛爭議一不管是案件數 目或其內容都一樣, 必須大量仰賴各式醫療糾紛ADR才行。 針對醫療糾紛以及醫病關係改善, 應該全方位一訴訟及訴 訟外解決機制各種方式均具備以竟全功。而且醫療糾紛處
理必須顧及醫療安全及醫療品質的提升, 唯有優質的調解 才能達成這種需求。證之美、日經驗 [25-26], 我們認 為CSM的推廣必能有助於提升醫療安全與醫療品質, 成效 待後續研究證實。

立法方向在醫療糾紛處理辦法草案雖有擬定關懷小 組之推動, 不過若流於形式則無法作一個真正的改革進展。 希望能在實質面採行溝通關懷調解理念及推動相關教育 培訓有所貢獻。

更希望能繼續努力以立法引導調解, 賦以明確之法律 地位, 構建調解機制的公正程式, 增強公信力。並加強促 進調解機制與專業團體合作, 重視醫療糾紛的教育與預防, 促使調解機制與醫療責任保險相結合, 且除了醫療糾紛的 處理外與補償救濟要能並重。期使醫療環境改善, 醫事人 員安心從事醫療專業、大眾有安全貼心的醫療服務, 這種 雙贏局面早日來臨。

\section{参考文献}

[1] The 2016 Global Pound Conference Series! An invitation to participate in shaping dispute resolution and access to justice around the world [ Z ]

https://imimediation. org/private/downloads/RxVuFnE VsYdCIrAJhq7s1w/EE_s_final_version_to_post_on_Port al_GPC_post_17_May_2015.pdf, Latest review date:2015/11/16.

［2］李念祖, 訴訟外紛爭解決機制導論 [M] , 收錄於李念祖、 李家慶主編之訴訟外紛爭解決機制, 臺北市, 三民書局, 2012.2: 頁3-21。

[3] 鄧一恒, 中國社區調解的民俗志研究 [Z] , 上外博士沙龍 第93期。

http://www. ora. shisu. edu. cn/s/89/t/121/6b/8c/info2 7532. htm，最後檢視日2015/11/15。

[4] International Mediation Institute 網站資料 [ Z ] https://imimediation. org/time-for-another-big-bang, 最後檢視日：2015/11/02。

[5] Zena D, Zumeta, J. D. Styles of Mediation: Facilitative, Evaluative and Transformative Mediation. [Z]

https://imimediation. org/mediation-styles, Latest review date:2015/11/16.

[6] Spangler, Brad. "Problem-Solving Mediation." Beyond Intractability. [M] Eds. Guy Burgess and Heidi Burgess. Conflict Information Consortium, University of Colorado, Boulder. Posted: September 2003 〈http://www. beyondintractability. org/essay/problem -solving-mediation $\rangle$. Latest review date:2015/11/16.

[7] John Winslade \& Gerald Monk, A New Approach to Conflict Resolution [M], California, Jossey-Basse Inc., 2004. 
[8] 莊均緯, 調解制度及技巧-促進式調解與評價式調解 [J], 技師報，2011/9/10，770期，台灣土木技師公會發行， www. twce. org. tw/modules/freecontent/include. php?fn ame=twce/paper $/ 770 / 2-1$. htm, 最後檢視日 $2015 / 11 / 12$ 。

[9] 冷函芸, 臺灣訴訟外調解之機制與實踐 [J]，法令月刊, 2013年，第64卷，（7期）：頁114-142。

[10］中西淑美, Mediation歷史背景理念: 1. Mediation発展 [ J ] ，醫療安全, Dec. 2008, Vol. 5(No. 4)：頁34。

[11］和田仁孝、中西淑美著，醫療促進溝通：由敘事著手的衝 突管理 $[\mathrm{M}]$ ，黃羿文、李訓承等翻譯，臺北市，原水文化 出版, 2013/11/14。

[12] Roger Fisher, William L. Ury, Bruce Patton, Getting to Yes: Negotiating Agreement Without Giving In. [M] $2^{\text {nd }}$ ed. London, Penguin books, 1991.

[13］李詩應、陳永綺, 醫療關懷調解模式一從當事人支援角度出 發 $[M]$, 收集於陳學德主編, 醫療糾紛處理之法制與實證: 醫療糾紛處理新思維 (三), 2015/11, 台北, 元照出版社, 頁1-43。

[14] 衛福部修正《醫糾法》草案, 醫界質疑未減 [ Z ] http://www. appledaily. com. tw/realtimenews/article/ new $/ 20150516 / 611561 /$ ，最後檢視日2015/11/12。

[15］20150524醫改會出席醫事法學會主辦〈醫糾法研討會〉報告 [R] http://www. thrf. org. tw/Page_Show. asp?Page_ID=2080, 最 後檢視日2015/11/12。

[16]「生育事故救濟試辦計畫」成效斐然, 降低產科醫療糾紛, 改 善 執 業 環 境 $[\mathrm{R}]$, 參 http://www. mohw. gov. tw/cht/ministry/DM2_P. aspx?f_1 ist_no $=7 \&$ fod_1ist_no $=5312 \&$ doc_no $=49281$, 最後檢視日 $2015 / 11 / 12$ 。
[17] Milton Mayeroff, On Caring, 翻譯: 關懷的力量 [M] , 陳正芬譯，台北市，經濟新潮社出版，2011年。

[18] 李詩應、陳永綺, 當醫療遇上衝突糾紛, 訴訟是最好的解 決方法? [M] 台北市, 原水出版社, 2013-10-24。

[19] Hunter M. International commercial dispute resolution: the challenge of the twenty-first century. [J] Arbitration International. 2000, Vol. 16 (No. 1) : PP. 379-392.

[20] 黃惠鈴, 天下雜誌, 俊子精神 牽起醫病和諧的手 $[\mathrm{J}]$, 台北，2014/02/19，第541期，頁160-163。

[21] 孫容萍, 今周刊, 陳永綺, 打造醫病和諧橋梁的推手 $[\mathrm{J}]$, 台北，第895期，2014/02/11，頁60-62。

[22］李藹芬，媽媽寶寶，李詩應、陳永綺攜手走在促進醫病和 諧之路 [J]，台北，第325期，2014/3，頁218-220。

[23] 林篵婷, 新新聞雜誌, 【封面故事】這一次換成自己是家 屬 感受特別痛 $[J]$ 。台北, 2015/05/27, 1473期, 頁22-23。

[24] 黃漢華, 遠見雜誌: 醫病和諧的推手, 李詩應、陳永綺醫 師，赴日取經 以溝通取代訴訟 [J]，第349期，2015年7 月號，頁72-74。

[25] C.S. Hyman, Mediation \& medical malpractice: Why plaintiffs, hospital \& physicians should be at the table. [ J ] Dispute Resolution J. 2011 (No. 32) : pp. 1-4.

[26] 和田仁孝、中西淑美, 医療メデイエーション [M], 東京, Signe, 2012/6/15，第一版第二刷，頁：41-42. 